\title{
Oil-Water Emulsion Separation Using Nanoparticle-Coated Polystyrene Membrane
}

\author{
Chioma Deborah Mbakaogu, Ngozi Claribelle Nwogu, Nkemakolam Chinedu Izuwa, \\ Stanley Toochukwu Ekwueme
}

Department of Petroleum Engineering, Federal University of Technology, Owerri, Nigeria

\section{Email address:}

chiomambakaogu@gmail.com (C. D. Mbakaogu),nwogungozi2@gmail.com (N. C. Nwogu), ncizuwa@yahoo.com (N. C. Izuwa), stanleyekwueme@yahoo.com (S. T. Ekwueme)

\section{To cite this article:}

Chioma Deborah Mbakaogu, Ngozi Claribelle Nwogu, Nkemakolam Chinedu Izuwa, Stanley Toochukwu Ekwueme. Oil-Water Emulsion Separation Using Nanoparticle-Coated Polystyrene Membrane. International Journal of Oil, Gas and Coal Engineering.

Vol. 8, No. 6, 2020, pp. 151-156. doi: 10.11648/j.ogce.20200806.15

Received: September 21, 2020; Accepted: October 5, 2020; Published: November 27, 2020

\begin{abstract}
The demand for membranes have increased enormously in the last decades due to increased applicability in many industrial activities. In the oil and gas industry, filtration membranes gain popularity over other types of membranes due to their usage in separation of oil-water emulsion using microfiltration and/or ultrafiltration techniques. Researchers have geared interest in the development of better performance membranes aimed at improving the efficiency of separation and antifouling properties. Developments in nanotechnology has made available nanoparticles which are used to further enhance the properties and performance of membranes, adding credence to membrane usage in emulsion separation. In this work, Polystyrene membrane of size $0.1 \mu \mathrm{m}$ is enhanced by coating with Aluminium oxide nanoparticle for improve fouling resistance properties and separation efficiency. Experiments were conducted in separation of oil-water emulsion using the prepared composite membrane system. Results show that the membrane system yields $97.86 \%$ and $97.54 \%$ efficiency in terms of oil rejection for a pressure application of $60 \%$ stroke and $80 \%$ stroke respectively while the permeation fluxes are $2.433 \mathrm{ml} / \mathrm{cm}^{2}-\mathrm{min}$ and 1.944 $\mathrm{ml} / \mathrm{cm}^{2}$-min for $80 \%$ stroke and $60 \%$ stroke pressure applications respectively. The results reveal that increase in pressure has less effect in the membrane efficiency. The application of aluminum oxide coating increased the efficiency of the membrane and reduced its fouling characteristics.
\end{abstract}

Keywords: Aluminium Oxide, Emulsion, Nanoparticles, Membranes, Polystyrene

\section{Introduction}

The development of technology to separate oil from water is vital when dealing with oil-water emulsions. An emulsion is a heterogeneous mixture of two immiscible liquids with one intimately dispersed in the other as droplets [1]. Membranes have been studied and are especially encountered in many industrial processes such as pharmaceuticals, food processing, desalination, wastewater treatment, chemical etc. In the oil industry, emulsions occur between water and crude oil in drilling, processing, production and transportation phases of oil and gas operations. Oil-water emulsion can be stable or unstable depending on the emulsifying agents present in the crude oil system. Furthermore emulsion can either be oil in water when oil is the dispersed phased, water in oil when water is the dispersed phase or mixed emulsion

\section{$[2,3]$.}

Over the years, so much attention has been given to means of separating oil-water emulsion because of the inherent difficulties which it portrays. One such difficulty is the disposal problem which leads to pollution of the ecosystem. Another demerit of oil and water emulsion is the loss of economic benefits accruing from the oil trap in the emulsion system. These problems could be handled and minimized if appropriate demulsification methods are applied [4, 5]. Researchers have found out that using membranes for oil/water emulsion separation is more efficient when compared to conventional techniques such as gravity settling, coagulation, flotation, flocculation, ozonation, and chemical methods. These conventional methods have become ineffective in treatment of oil/water emulsion due to high operational cost, higher energy consumption, lower 
efficiency and the problem of getting secondary pollutants as by-products $[6,7]$. Emulsions employed in separation of oilwater emulsion are filtration-type membranes which are employed in microfiltration and ultrafiltration processes.

All membrane separations rely on a driving force across the membrane to induce the flow or flux and a separation factor which prevents some materials from crossing. Pressure is the most common driving force, in that case, low-pressure permeate stream becomes enriched by rapidly diffusing components while the slower components are concentrated in the retentate stream. Either permeate or retentate could be the product $[8,9]$.

On basis of the materials used, membranes can be divided into 3 or 4 categories which includes polymers membranes, metallic membranes, ceramic membranes (metal oxide, carbon glass) and liquid membranes. Polymer membranes have been popular in use as filtration materials. Polymers such as polyvinylidene fluoride (PVDF), Polysulfone (PSf), Polyethersulfone (PES) etc. have been applied in separation of oil-water emulsions. Most polymeric membranes owing to their intrinsic properties are oleophilic which means that they attract oil to their surfaces. Oil retention to polymeric membrane surfaces have been shown to be the cause of membrane fouling [10]. To improve the hydrophilicity and antifouling performance of polymeric membranes, the membrane can be blended with hydrophilic components or surface modification of the membrane surface can be done. Ceramic membranes gained importance because of their high chemical, thermal and mechanical stabilities, which make them suitable for use in harsh conditions such as corrosive and high temperature environments. But due to the limitation of their pore sizes, using ceramic membranes oil-water emulsion separation poses risk of severe fouling problems and low fluxes. Notwithstanding, Ceramic materials such as silicium carbide, zirconium oxide, titanium oxide etc. endure harsh temperature conditions and exhibit stable performance in solvent medium [11].

An Ideal membrane material should have high selectivity, permeate flux, stability and fouling resistance. However, the major problem in filtration membranes for oil-water separation is membrane fouling, caused by surfactant adsorption or pore plugging by oil droplets which leads to decreased permeation flux. In most cases, there is inevitable requirement to clean the membrane $[12,13]$. Membrane cleaning involves extra maintenance downtime, chemicals and energy. This adds to the operation costs and may threaten the benefits of membrane separation. Developments in nanotechnology has made available inorganic nanoparticles which have proven to be helpful in improving membrane permeability and fouling resistance by either changing the membrane pore structure or increasing its hydrophilicity.

Polystyrene (PS) is a synthetic aromatic hydrocarbon polymer that is produced from the monomer known as styrene. Chemically, polystyrene is a long chain hydrocarbon wherein alternating carbon centers are attached to phenyl groups. Polystyrene (PS) is one of the most widely used plastics, with global industrial annual productions of several million tonnes. Polystyrene is generally considered to be non-biodegradable and is a major component of plastic debris in the ocean, and the principal cause of white pollution. Because of its hydrophobic and oleophilic properties, PS exhibits high prospects for as oil absorbent. PS material with high surface area is highly demanded in the absorption application for oil-water emulsion separation.

Yang et al [14] studied $\mathrm{TiO}_{2}$ nanoparticles. They used the nanoparticle in coating a Polysulfone ultrafiltration membrane which was successfully applied in the separation of kerosene/water emulsion. In addition, the membrane was observed to have enhanced anti-fouling properties.

$\mathrm{Li}$ et al [15] blended $\mathrm{Al}_{2} \mathrm{O}_{3}$ nanoparticles with PVDF-UF membranes. He observed upon addition of $\mathrm{Al}_{2} \mathrm{O}_{3}$ nanoparticles increased the hydrophilicity of the PVDF membrane but had no effect on the effective pore size and porosity of the membrane.

Liu et al [16] researched on "efficient oil/water separation membrane derived from super-flexible and superhydrophilic core-shell organic/inorganic nanofibrous architectures". They manufactured superhydrophilic and underwater superoleophobic organic/inorganic nanofibrous membranes using a scale-up fabrication method. The membrane that was synthesized retains a delicate organic core of PVDF-HFP and an inorganic shell of a $\mathrm{CuO}$ nanosheet structure, this provides super-flexible characteristics owing to the merits of PVDFHFP backbones, and superhydrophilic functions contributed by the extremely rough surface of a $\mathrm{CuO}$ nanosheet anchored on flexible PVDF-HFP. This organic core and inorganic shell architecture not only improves membrane performance in terms of antifouling, high flux, and low energy consumption, but also prolongs the lifespan by enhancing its mechanical strength and alkaline resistance to widen its applicability. The resultant membrane exhibits good oil/water separation efficiency in terms of oil rejection of more than $99.7 \%$, together with excellent anti-fouling features for different oil/water emulsions.

In this work, Polystyrene membrane material engineered with Aluminium oxide nanoparticle coatings is used in the separation of oil-water emulsion.

Table 1. Properties of common Polystyrene membrane material for emulsion separation [17].

\begin{tabular}{|c|c|c|c|c|c|c|c|}
\hline Size & $\begin{array}{l}\text { Pore Density } \\
\left(\text { pores } / \mathbf{c m}^{2}\right)\end{array}$ & $\begin{array}{l}\text { Open Area } \\
(\%)\end{array}$ & $\begin{array}{l}\text { Nom. } \\
\text { Thickness }(\mu \mathrm{m})\end{array}$ & $\begin{array}{l}\text { Nom. Weight } \\
\left(\mathrm{mg} / \mathrm{cm}^{2}\right)\end{array}$ & $\begin{array}{l}\text { Bubble Point } \\
\text { (psi) }\end{array}$ & $\begin{array}{l}\text { Water Flow Rate } \\
\left(\mathrm{mL} / \mathrm{min} / \mathrm{cm}^{2}\right)\end{array}$ & $\begin{array}{l}\text { Air Flow Rate } \\
\left(\mathrm{L} / \mathrm{min} / \mathrm{cm}^{2}\right)\end{array}$ \\
\hline $0.1 \mu \mathrm{m}$ & $4 \times 10^{8}$ & 3.1 & 10 & 0.8 & 30 & 2.5 & 1.5 \\
\hline $0.2 \mu \mathrm{m}$ & $3 \times 10^{8}$ & 9.4 & 10 & 1.3 & 20 & 10 & 3 \\
\hline $0.4 \mu \mathrm{m}$ & $1 \times 10^{8}$ & 12.6 & 10 & 1.2 & 12 & 33 & 7.5 \\
\hline $0.8 \mu \mathrm{m}$ & $3 \times 10^{7}$ & 15.1 & 9 & 1.1 & 7 & 90 & 18 \\
\hline $1.0 \mu \mathrm{m}$ & $2 \times 10^{7}$ & 15.7 & 11 & 1.3 & 6 & 130 & 20 \\
\hline
\end{tabular}




\begin{tabular}{|c|c|c|c|c|c|c|c|}
\hline Size & $\begin{array}{l}\text { Pore Density } \\
\left(\text { pores/ } \mathbf{c m}^{2}\right)\end{array}$ & $\begin{array}{l}\text { Open Area } \\
(\%)\end{array}$ & $\begin{array}{l}\text { Nom. } \\
\text { Thickness }(\mu \mathrm{m})\end{array}$ & $\begin{array}{l}\text { Nom. Weight } \\
\left(\mathbf{m g} / \mathrm{cm}^{2}\right)\end{array}$ & $\begin{array}{l}\text { Bubble Point } \\
\text { (psi) }\end{array}$ & $\begin{array}{l}\text { Water Flow Rate } \\
\left(\mathrm{mL} / \mathbf{m i n} / \mathbf{c m}^{2}\right)\end{array}$ & $\begin{array}{l}\text { Air Flow Rate } \\
\left(\mathrm{L} / \mathbf{m i n} / \mathrm{cm}^{2}\right)\end{array}$ \\
\hline $2.0 \mu \mathrm{m}$ & $2 \times 10^{6}$ & 6.3 & 10 & 1.3 & 3 & 300 & 16.5 \\
\hline $3.0 \mu \mathrm{m}$ & $2 \times 10^{6}$ & 14.1 & 9 & 1.1 & 2 & 440 & 37.5 \\
\hline $5.0 \mu \mathrm{m}$ & $4 \times 10^{5}$ & 7.9 & 10 & 1.3 & 1.2 & 700 & 30 \\
\hline $8.0 \mu \mathrm{m}$ & $1 \times 10^{5}$ & 5.0 & 7 & 1.0 & 0.7 & 1000 & 30 \\
\hline $10.0 \mu \mathrm{m}$ & $1 \times 10^{5}$ & 7.9 & 9 & 1.3 & 0.9 & 1150 & 34.5 \\
\hline
\end{tabular}

Table 1 gives the properties of several sizes of Polystyrene membrane for application in filtration processes. The water flowrate and air flowrate represent the volume of water and air that can pass through the membrane pores on application of pressure (at bubble point).

\section{Materials and Methods}

\subsection{Materials}

The polystyrene (PS) membrane material of size $0.1 \mu \mathrm{m}$ was purchased from the market alongside the Aluminum oxide nanoparticles. Crude oil sample used was sourced from Niger Delta flowing well. Other materials for the experiments used such as Iso-Hexane, sealant, Petroleum ether and silver nitrate were purchased from the market.

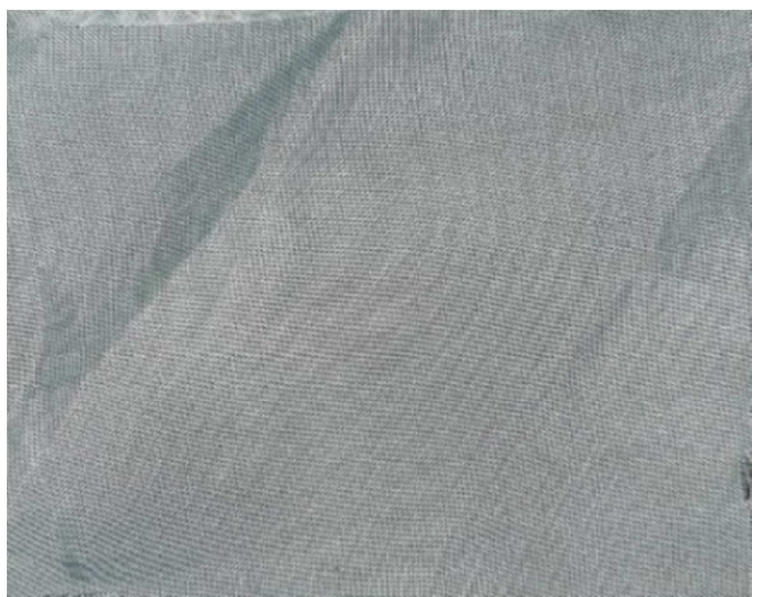

Figure 1. Polystyrene membrane support material.

\subsection{Experimental Process}

The experimental process comprise the following i) preparation of the crude oil emulsion mixture ii) preparation of the nanoparticle mixture and coating of the membrane support material iii) Actual oil/water emulsion separation.

For the crude oil emulsion preparation, crude oil of $50 \mathrm{ml}$ was measured and poured into a beaker. $500 \mathrm{ml}$ of deionized water was added to the crude oil. The resulting mixture was stirred thoroughly to obtain a homogenous oil/water emulsion. The Mixture was then blended in a high speed blender at 20,000rpm (high rotational speed) for 1 minute. The oil droplet size was then measured by an optical microcopy method.

Next was the preparation of the Aluminium oxide nanoparticle and coating of the membrane material: In doing this, $5 \mathrm{~g}$ of silicon sealant was dissolved in $10 \mathrm{ml}$ of isohexane. $40 \mathrm{~g}$ of Aluminium oxide nanoparticle was put into
$500 \mathrm{ml}$ beaker. Then $40 \mathrm{~g}$ of the Aluminium oxide nanoparticle was added into the silicon sealant-iso-hexane solution at room temperature and stored for 1 minute to form a paste-like slurry. The resulting mixture was then stirred vigorously and cast on the top of each of the membrane support and left for 10 minutes to settle.

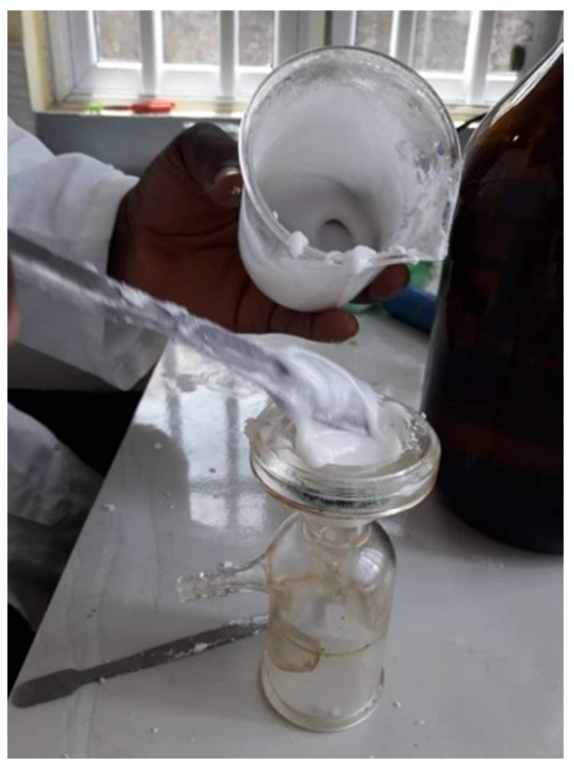

Figure 2. Casting on the composite membrane.

The coated membrane sample was fixed to the membrane filtration apparatus and then allowed to dry in open air for about 1 hour. The prepared oil-water emulsion was stirred for 60 minutes to achieve a homogenous mixture under ambient conditions. The membranes to be used were pre-wetted before used for the separation. The emulsion was poured into a measuring cylinder in the filtration apparatus. The procedure was carried out under $80 \%$ stroke and $60 \%$ strokes pressure using vacuum pump.

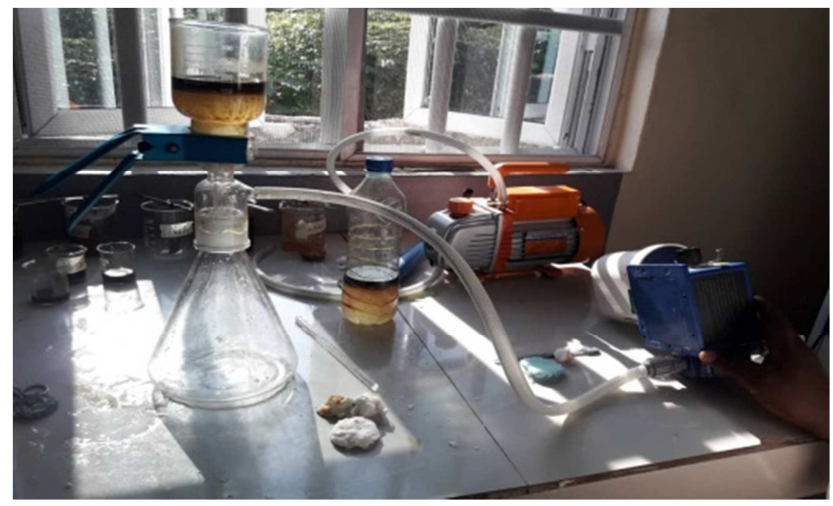

Figure 3. Membrane separation process using vacuum pump. 
Figure 3 gives a description of the membrane system undergoing separation. Due to applied pressure from the vacuum pump, the emulsion mixture in the filtration apparatus is pressurized and filtration commences. Since the polystyrene membrane material used is oleophilic, the setup allows passage of water while oil is retained at the membrane material.

\section{Results and Discussion}

The Result for Polystyrene membrane material for $80 \%$ stroke and $60 \%$ stroke is given in table 2 .

Table 2. Experimental results.

\begin{tabular}{llll}
\hline \multirow{2}{*}{ Parameter } & Raw sample & Polystyrene & \\
\cline { 2 - 4 } & $\mathbf{8 0 \%}$ stroke & $\mathbf{6 0 \%}$ stroke \\
\hline $\mathrm{pH}$ & 5.89 & 2.5 & 6.65 \\
Conductivity, S/cm & 33 & 44.95 & 50 \\
Turbidity, NTU & 15.7 & 49 & 57 \\
Chemical Oxygen Demand (COD), mg/l & 7800 & 1740 & 5520 \\
Viscosity, mPa.s & 19.9 & 22.33 & 20.75 \\
Filtration time, min & - & 7 & 12 \\
Oil Content in filtrate, $\%$ & 14 & 0.4 & 0.34 \\
Volume of Filtrate, ml & - & 172 & 176 \\
Volume retained, ml & - & 25 & 20 \\
Total volume of emulsion used, ml & 200 & - & - \\
Volume absorbed by membrane & - & 3 & 4 \\
Volume of oil content in filtrate & - & 0.69 & 0.6 \\
Separation Efficiency & & 97.54 & 97.86 \\
Permeation Flux, ml/cm ${ }^{2}$-min & & 2.443 & 1.944 \\
Average Filtrate Flowrate, ml/min & 24.57 & 14.67 \\
\hline
\end{tabular}

Table 2 gives the summary of experimental results using polystyrene to separate crude oil emulsion. The separation processes were facilitated by pressure applied using vacuum pump. Pressures were applied for $60 \%$ stroke and $80 \%$ stroke on the polystyrene membrane material. From table 2, the volumes of liquid absorbed by the membrane materials are $3 \mathrm{ml}$ and $4 \mathrm{ml}$ for $80 \%$ stroke and $60 \%$ stroke respectively. The volumes of oil in the filtrate are $0.69 \mathrm{ml}$ and $0.6 \mathrm{ml}$ for $80 \%$ stroke and $60 \%$ stroke respectively; the separation efficiencies in terms of oil rejection are $97.54 \%$ and $97.86 \%$ for $80 \%$ stroke and $60 \%$ stroke respectively. Thus, there is no appreciable difference in the change in pressure with efficiency of the separation as evident from the result. The permeation fluxes are $2.443 \mathrm{ml} / \mathrm{cm}^{2}$-min and $1.944 \mathrm{ml} / \mathrm{cm}^{2}$ min for $80 \%$ stroke and $60 \%$ stroke respectively. The average flowrates of the filtrate are $24.57 \mathrm{ml} / \mathrm{min}$ and $14.67 \mathrm{ml} / \mathrm{min}$ for the $80 \%$ stroke and $60 \%$ stroke respectively.

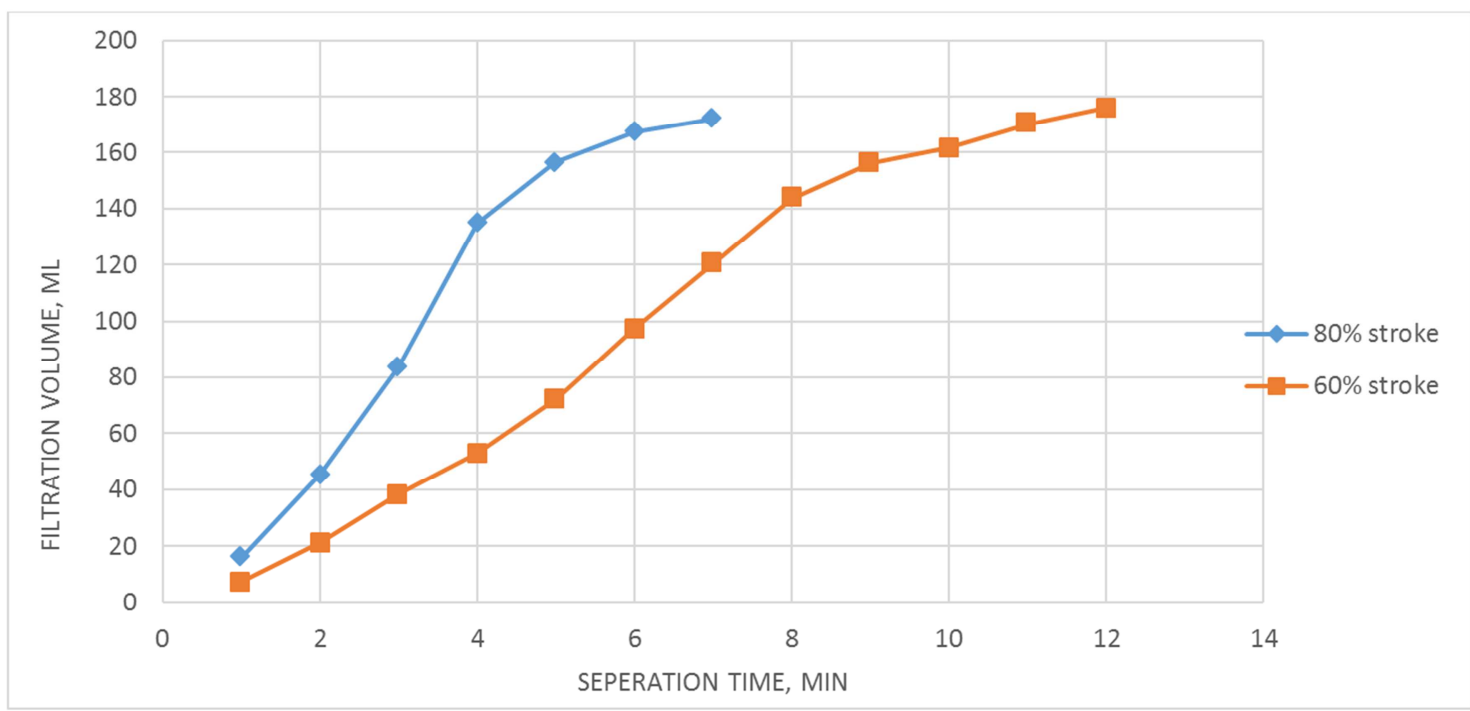

Figure 4. Graph of filtrate volume and separation time for Polystyrene membrane material.

From figure 4 , it can be observed that the $80 \%$ stroke yields more filtrate volume at first, but it lasted for less time compared to $60 \%$. The $60 \%$ stroke has less flowrate but with higher recovery of filtrate volume owing to more time of separation. Thus more time was needed to achieve higher filtration volume as a result of less pressure applied. Also, from figure 4 , more water was removed by using a pressure of $60 \%$ than a pressure of $80 \%$ stroke. This is because at higher pressures, the oil phase may deform and acquire sufficient energy to pass through the membrane surface to the 
filtrate side even though the membrane surface is oleophilic.

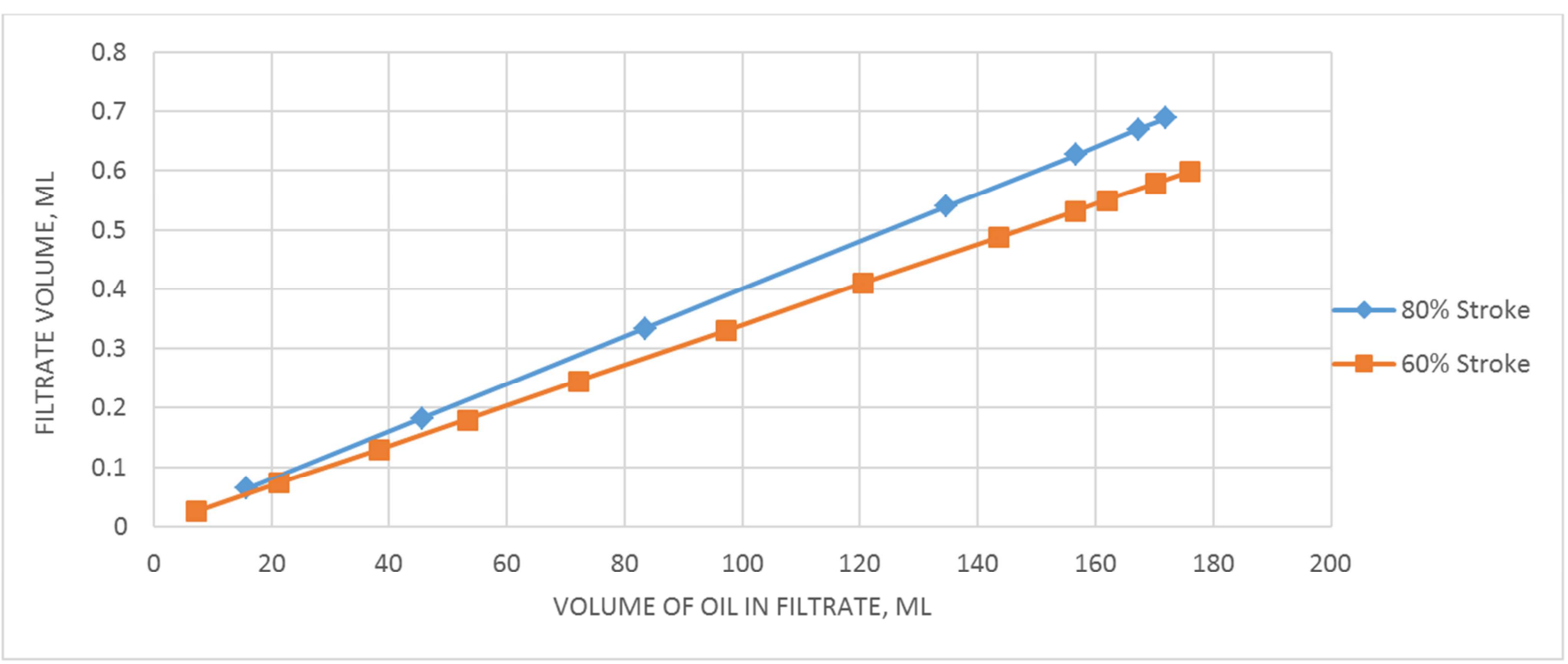

Figure 5. Graph of filtrate volume and volume of oil present in filtrate for Polystyrene membrane material.

Figure 5 clearly illustrates the production of more oil in the filtrate due to addition of higher pressures. As can be observed from the figure, the blue line representing the $80 \%$ stroke pressure application lies above the red line representing the $60 \%$ pressure application.

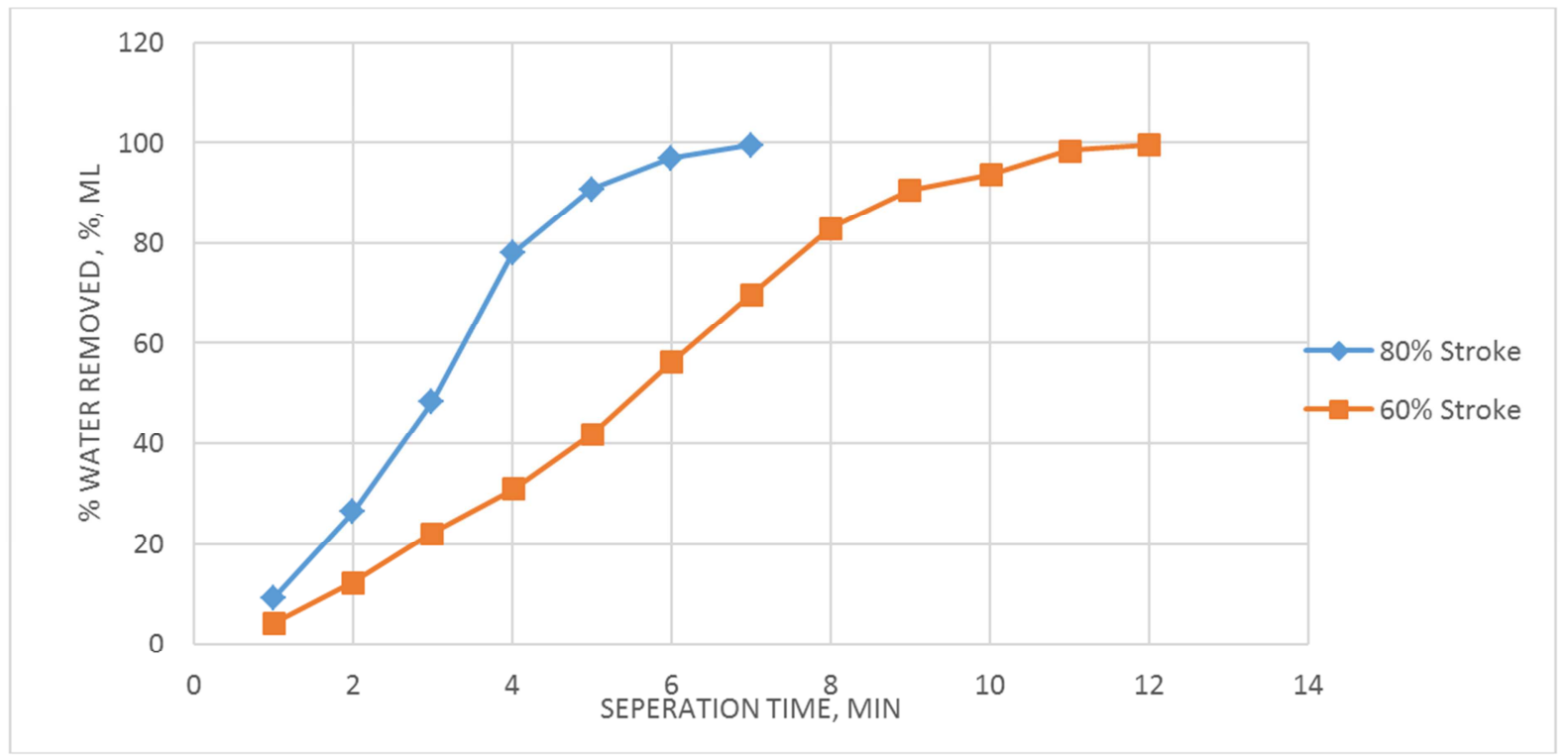

Figure 6. Graph of percentage water removal from the Polystyrene membrane material.

From figure 6 , the percentage water removed from $60 \%$ stroke is more than that for $80 \%$ stroke at the end of the separation process. But initially due to higher average flowrate as a result of higher pressure, more water per time was separated from the $80 \%$ stroke, but it only endured for less time compared to that of $60 \%$ stroke.

\section{Conclusion}

Polystyrene membrane material coated with Aluminum oxide nanoparticles have been studied relative to its application in the separation of crude oil emulsion. While polystyrene membrane shows good permeation flux, its efficiency in terms of oil rejection was greatly enhanced by coating with Aluminium oxide nanoparticles which apart from improvement in separation efficiency gives it more mechanical stability while improving its fouling resistance characteristics. The composite membrane exhibited very high oil rejection efficiency $97.86 \%$ for $80 \%$ stroke and $97.54 \%$ for $60 \%$ stroke. The efficiency is highly within the range of polymer membranes used for oil-water separation in literatures. It is expected that padding more sheets of polystyrene membrane will further increase the efficiency in terms of oil rejection. 


\section{Recommendation}

Polystyrene polymer membrane is recommended for use in separation of crude oil emulsion that frequently occur in oil gas activities in the Niger Delta. The membrane must be manufactured to be stable to withstand applied separation pressures. Furthermore, because of the oleophilic nature of Polystyrene membrane, coating with nanoparticles like aluminum oxide gives extra mechanical strength and antifouling resistance the membrane.

More research should focus on addition of a co-polymer to achieve a membrane-co-polymer-aluminum nanoparticle membrane construction for a higher efficient and durable membrane application for separation of more varieties of oil/water emulsions. Also padding sheets of Polystyrene membrane is expected to yield higher separation efficiency in terms of oil rejection.

\section{References}

[1] Abdel-Raouf M. E. (2012). Crude Oil Emulsions Composition Stability and Characterization, InTech Janeza, Croatia.

[2] Matsuyama Hideto and Yoshioka Tomohisa (2019). Development of ultrathin durable membrane for efficient oil and water separation. Journal of Material Chemistry.

[3] Zhu Yuzhang, Wang Dong, Jiang Lei, and Jin Jian. (2014). Recent progress in developing advanced membranes for emulsified oil/water separation. NPG Asia Materials. Nature publishing group. Vol 6.

[4] Mohammadian, E.; Taju Ariffin, T. S.; Azdarpour, A.; Hamidi, H.; Yusof, S.; Sabet, M.; Yahya, E. (2018). Demulsification of Light Malaysian Crude Oil Emulsions Using an Electric Field Method. Ind. Eng. Chem. Res., 57, 13247-13256.

[5] Roshan, N.; Ghader, S.; Rahimpour, M. R. (2018). Application of the response surface methodo logy for modeling demulsification of crude oil emulsion using a demulsifier. J. Dispers. Sci. Technol, 39, 700-710.

[6] Yu Qianqian, Wenbo Zhang, Xinyue Zhao, Guoliang Cao, Feng Liu, Xin Di, Haiyue Yang, Yazhou Wang and Chengyu Wang (2018). A Simple, Green Method to Fabricate Composite Membranes for Effective Oil-in-Water Emulsion Separation. Polymers.
[7] Tiron, L. G., Pintilie, S. C, Vlad, M., Birsan, I. G., and Baltă, S. (2017). Characterization of Polysulfone Membranes Prepared with Thermally Induced Phase Separation Technique. International Conference on Innovative Research, IOP Conf. Series: Materials Science and Engineering 209.

[8] Saki Seda \& Uzal Nigmet (2018). Preparation and characterization of $\mathrm{PSF} / \mathrm{PEI} / \mathrm{CaCO} 3$ nanocomposite membranes for oil/water separation. Environmental Science and Pollution Research. Springer-Verlag GmbH Germany.

[9] Wang Guowei, Yu Bin, Chen Shiguo \& Uyama Hiroshi (2017). Template-free synthesis of polystyrene monoliths for the removal of oil-in-water emulsion. Scientific reports |7: 6534| doi: 10.1038/s41598-017-06572-7.

[10] Shehzad, F.; Hussein, I. A.; Kamal, M. S.; Ahmad, W.; Sultan, A. S.; Nasser, M. S. (2018). Polymeric surfactants and emerging alternatives used in the demulsification of produced water: A review. Polym. Rev., 58, 63-101.

[11] Borisov Ilya, Ovcharova Anna, Bakhtin Danila, Bazhenov Stepan, Volkov Alexey, Ibragimov Rustem, Gallyamov Rustem, Bondarenko Galina, Mozhchil Rais, Bildyukevich Alexandr and Volkov Vladimir (2017). Development of Polysulfone Hollow Fiber Porous Supports for High Flux Composite Membranes: Air Plasma and Piranha Etching.

[12] Oh S, Ki S, Ryu S, Shin MC, Lee J, Lee C, Nam Y.(2019). Performance Analysis of Gravity-Driven Oil-Water Separation Using Membranes with Special Wettability. ACS Publications, USA.

[13] Saad, M. A. Kamil, Mohammed Abdurahman, N. H. Yunus, R. $\mathrm{M}$ and Awad, O. I. (2019). An Overview of Recent Advances in State-of-the-Art Techniques in the Demulsification of Crude Oil Emulsions. Processes 2019, 7, 470.

[14] Yang Y. N., Zhang, H. X., Wang, P., Zheng, Q. Z. \& Li, J., (2007) Journal of Membrane Science. 288, 231.

[15] Li, X. Y. Hu, D. Huang, K. Yang, C. F. (2014). J. Mater. Chem. A, 2, 11830 .

[16] Liu Zhi, Qin Detao, Zhao Jianghui, Feng Quan, Li Zhengtao, Bai Hongwei, and Sun Darren D. (2019). Efficient Oil/Water Separation Membrane Derived from Super-Flexible and Superhydrophilic Core-Shell Organic/Inorganic Nanofibrous Architectures. Polymers (Basel) vol. 11 (6).

[17] Sterlitech Corporation (2019). Hydrophilic Polyester (PETE) Membrane Filters. https://www.sterlitech.com/. 